\title{
High Concentration Phenol Removal Using Freshwater Microalgae
}

\author{
Sulaiman Al-Zuhair ${ }^{1, *}$, Mustafa Nabil ${ }^{1}$, Yusuf Abdi $^{1}$, Murad Al Sayyed ${ }^{1}$ and Hanifa Taher $^{2}$ \\ ${ }^{1}$ Chemical and Petroleum Engineering Department, UAE University, 15551 Al Ain, UAE \\ ${ }^{2}$ Chemical Engineering Department, Masdar Institute, Abu Dhabi, UAE
}

\begin{abstract}
The ability of three freshwater microalgae strains, namely Chlorella $s p$., Pseudochlorococcum $s p$. and Chlamydomonas sp. to grow in water containing different concentrations of phenol has been tested. The effectiveness of the selected strains to utilize the phenol as a carbon source and reduce its concentration has also been assessed. The phenol removal efficiency and cells growth rates were evaluated at different initial phenol concentrations, in the range of $100-450 \mathrm{ppm}$. It was found that growing, under a reduced illumination condition, increased the inhibition onset concentration, enhanced the phenol removal and allowed the strains to tolerate higher phenol concentrations reaching $450 \mathrm{ppm}$. In the tested range of the phenol concentrations, Chlamydomonas $s p$. has shown to have the highest specific growth rate of 0.59 day $^{-1}$, whereas Pseudochlorococcum sp showed the highest phenol removal rate of $166 \mathrm{ppm}^{\text {day }}{ }^{-1}$. Three kinetics models that incorporate substrate inhibition were tested to describe the growth, which show almost identical fittings.
\end{abstract}

Keywords: Microalgae, Phenol bioremediation, Wastewater treatment, Growth kinetics, Substrate Inhibition, Light limitation.

\section{INTRODUCTION}

Phenol is a primary hazardous organic pollutant, founds in the wastewater of various industries, including the petroleum refinery [1]. Typical concentration of phenol in petroleum refinery wastewater is in the range of 13-88 ppm [2]. Phenol, which is a soluble compound in water, is considered carcinogenic to humans, and fatal to marine lives, if found in aquatic systems at concentrations as low as 5-25 ppm [3].

Many treatment processes have been tested for the removal of phenol, which have shown that the compound is difficult to remove. Biological degradation of phenol found in wastewater is a promising method that results in complete removal at a wide range of concentrations $[1,3,4]$. Majority of phenol biodegradation studies were carried out using bacteria from Pseudomonas genus, due to their high removal efficiency [3]. However, these bacteria are pathogenic and cause diseases in humans, plants and fish [5]. It is important thus to prevent the bacteria from escaping with the effluent treated water, and to achieve that, the bacteria have been used in immobilized form [6,7]. By this, the water contamination with the bacteria was reduced but not completely eliminated. In addition, the grown bacteria do not have any obvious commercial value. It would be useful therefore to find an alternative that shows a comparable performance, which is less harmful on one hand and can be used to produce valuable products on the other.

*Address correspondence to this author at the Chemical and Petroleum Engineering Department, UAE University, 15551 AI Ain, UAE;

Tel: +97137135319; E-mail: s.alzuhair@uaeu.ac.ae
Microalgae appear to be the best alternative in this regard, since the produced biomass, which is not harmful, can readily be used to produce lipids, proteins and pigment. The former product can be used for biodiesel production and the latter two products have uses in pharmaceutical and food industries. In addition, microalgae application in many chemical and environmental application have proven to be effective and more economical [8]. In recent years, microalgae research and applications have experienced a tremendous increase [9].

Phenol degradation by microalgae have been reported by strains of Chlorella sp., Scenedesmus obliqus and Spirulina maxima [10], Ochromonas danica [11], Ankistrodesmus braunii and Scenedesmus quadricauda [12], Chlorella vulgaris [13,14], Chlorella VT-1 [15], Volvox aureus, Lyngba lagerlerimi, Nostoc linkia, and Oscillatoria rubescens [16]. However, none of the above studies have reported algal growth kinetics in phenol. A recent work done by Das et al. [17] was the first to include such a kinetics study, but was done on a single strain of Chlorella pyrenoidosa. The strain was found to be inhibited at phenol concentration above $125 \mathrm{ppm}$, and hence the work of Das et al. [17] was limited to phenol concentration of $200 \mathrm{ppm}$. The main objective of this work is to test the ability of other microalgae strains, namely Chlorella sp., Pseudochlorococcum sp. and Chlamydomonas sp. to grow in wastewater containing a wider range of phenol to test their phenol removal efficiencies. In addition, enhancement heterotrophic growth, to direct the microalgae to utilize the phenol as a sole carbon source, by limiting the light is also tested. 


\section{MATERIALS AND METHODS}

\subsection{Strains and Culture Media}

Analytical grade phenol was purchased from $\mathrm{BDH}$ Chemicals, UK. All other chemicals were purchased from Sigma-Aldrich, USA. Freshwater strains, Chlorella $s p$. and Pseudochlorococcum sp. were obtained from a local marine research centre in Umm Al-Quwain, UAE. In addition, an indigenous microalgae strain isolated from Musffah, Abu Dhabi was kindly provided by Prof. Koroush Salihi, New York University in Abu Dhabi, UAE, which was identified to be Chlamydomonas sp. The strains were grown in modified Bold Bassel medium (3N-BBM) [18]. It must be noted that this medium does not contain any carbon source, which is importnat in order to force the microalgae to use phenol as a carbon source.

\subsection{Experimental Set-Up}

The strains were grown in $100 \mathrm{ml}$ medium placed in $250 \mathrm{ml}$ Erlenmeyer flasks, which were placed in temperature controlled shaking water bath (LabTech, DaihanlabTech Co. Itd., Koreas) set at $30{ }^{\circ} \mathrm{C}$ and 90 rpm. To enhance heterotrophic growth, and direct the microalgae to utilize the phenol as a sole carbon source, the cultures were not subjected to excessive lighting, and the lighting was limited to that used to illuminate the lab. Each flask contained $90 \mathrm{ml}$ of medium containing different concentrations of phenol in the range of $100-450 \mathrm{ppm}$. The selected range of phenol concentration was chosen to be around that found in refinery wastewater. $10 \mathrm{ml}$ of microalgae inoculum, were then added to each flask to bring the total volume to $100 \mathrm{ml}$. To account for any abiotic loss of phenol, phenol media without algal cells were incubated under the same culture conditions, by adding $10 \mathrm{ml}$ distilled water, instead of microalgae suspension, to prepare control samples. At regular intervals, $2 \mathrm{ml}$ samples were withdrawn for biomass and phenol concentration determination.

\subsection{Analysis}

The biomass concentration was monitored daily by measuring the optical density at $680 \mathrm{~nm}$ wavelength using UV-spectrophotometer (UV-1800, Shimadzu, Japan). For spectrophotometric measurement, medium without microalgae was used as blank. The growth was determined by dividing the optical density at any time by the initial optical density, measured on day 0 . To measure the phenol concentration, the samples were centrifuged centrifugation at $6000 \mathrm{r} \mathrm{min}^{-1}$ for $15 \mathrm{~min}$ using multispeed centrifuge (IEC CL31, Thermo Scientific, USA) to remove the biomass. The supernatant was then collected to measure the phenol concentration using the same spectrophotometer at $270 \mathrm{~nm}$, which was calibrated using serial dilutions of standard phenol samples. The concentration of phenol was verified against results found using a Gas Chromatograph (Shimadzu 2010, Japan). The GC was equipped with capillary column (Stabilwax, $30 \mathrm{~m}$, $0.25 \mathrm{~mm}$ ID) and a flame ionization detector (FID), which was set at $250{ }^{\circ} \mathrm{C}$. The temperature program started at $100^{\circ} \mathrm{C}$ and increased at a rate of $20^{\circ} \mathrm{C} \min ^{-1}$ to $180^{\circ} \mathrm{C}$.

\subsection{Experimental Replication and Reproducibility of the Results}

Each experiment was repeated in duplicates, and the average values of the results were then presented. The repetition was performed using biologically separate biomass samples and not repeating the measurements of the same sample. The reproducibility of the experimental results was evaluated using the standard deviations shown as error bars in figures and errors values in tables.

\section{RESULTS AND DISCUSSION}

\subsection{Microalgae Growth}

The effect of initial phenol concentration on the growth of Chlorella sp., Pseudochlorococcum sp. and Chlamydomonas $s p$. is shown in Figure $\mathbf{1 a}, \mathbf{1 b}$, and $\mathbf{1 c}$, respectively. Values shown in the Figure are average values for experiments carried in dulicate at same conditions, and the lines are connections between the experimental data to show the trends. A lag phase of around 4 days was observed in the growth of Chlamydomonas $s p$., whereas it was less obvious for Chlorella sp. and Pseudochlorococcum sp. strains. It was also observed that the same lag phase existed regardless of the initial phenol concentration. This agrees with the results found by Das et al. [17], where lag phase existed when growing $C$. pyrenoidosa in phenol concentrations higher than $50 \mathrm{ppm}$.

From the growth curves, the specific growth rates were determined for the three strains as shown in Figure 2. Assuming the maintenance requirement for the limiting substrate to be small enough to be neglected, the specific growth rates, shown in Figure 2, were calculated from the slope of $\ln \left(X / X_{0}\right)$ versus time 

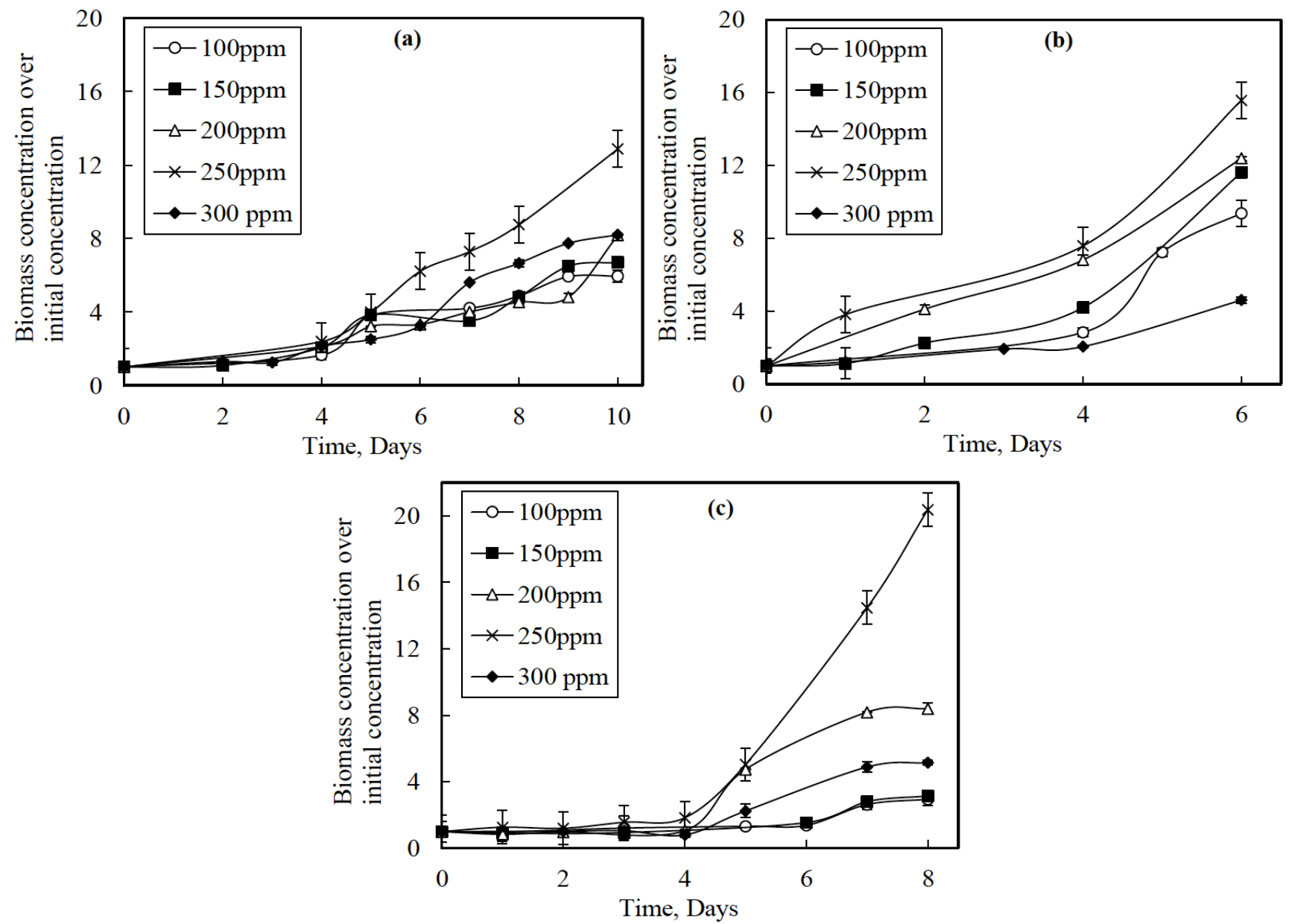

Figure 1: Biomass growth profile of (a) Chlorella sp., (b) Pseudochlorococcum sp. and (c) Chlamydomonas sp. at various initial phenol concentrations.

line, in the exponential growth region, where $X$ and $X_{0}$ are the biomass concentration at any time and at initial time, respectively.

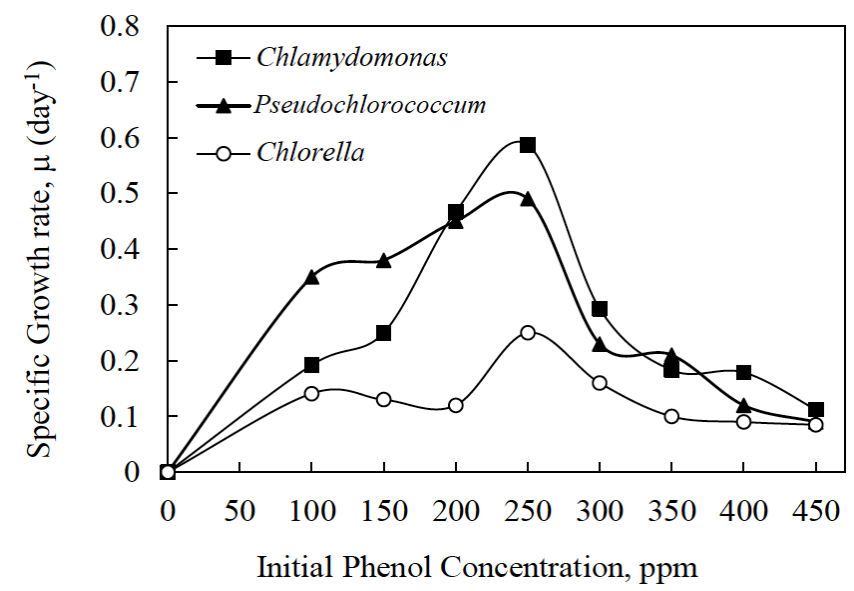

Figure 2: Specific growth rate of Chlorella $s p$. , Pseudochlorococcum sp. and Chlamydomonas sp. at various initial phenol concentrations.

The specific growth rate was found to increase with increase in phenol concentration until the highest value was reached at phenol concentration of $250 \mathrm{ppm}$. However, the growth rate was found to decline with increase in phenol concentration beyond $250 \mathrm{ppm}$, suggesting substrate inhibition effect of phenol. It was also interesting to notice that, although the microalgae growth rate dropped with at phenol concentration higher than $250 \mathrm{ppm}$. Yet, they were able to survive up to a concentration of as high as $450 \mathrm{ppm}$. Similar trend was also observed using $C$. pyrenoidosa [17], but the highest specific rate was reached at $125 \mathrm{ppm}$. The higher inhibition onset concentration observed in this work, compared to that found using $C$. pyrenoidosa [17], could be due to the enhanced heterotrophic growth condition at the lower light intensity, used in this work. This lower intensity however reduced the growth rate. The highest growth rates were found to be 0.25 , 0.49 and 0.59 day $^{-1}$ for Chlorella sp., Pseudochlorococcum sp. and Chlamydomonas sp., respectively, compared to that of $C$. pyrenoidosa subjected to excessive alternate illumination, which was found to be 0.65 day $^{-1}$ [17]. 

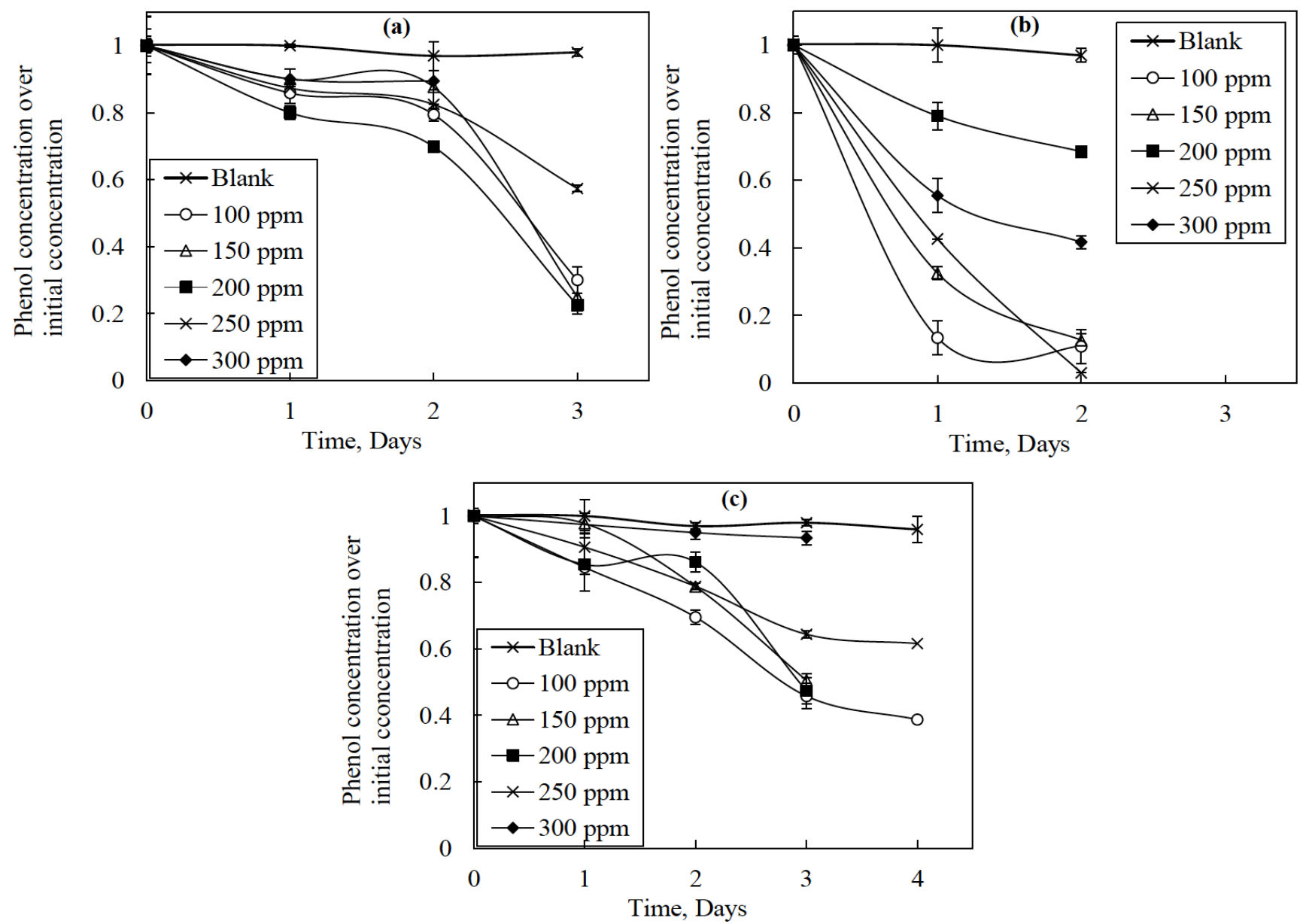

Figure 3: Phenol concentration profile of (a) Chlorella sp., (b) Pseudochlorococcum sp. and (c) Chlamydomonas sp. at various initial phenol concentrations.

\subsection{Phenol Degradation}

To determine the effectiveness of the tested strain for phenol degradation, the residual phenol was estimated at different times. The effect of initial phenol concentration on the drop of phenol using Chlorella sp., Pseudochlorococcum sp. and Chlamydomonas $s p$. is shown in Figure $\mathbf{3 a}, \mathbf{3 b}$, and $\mathbf{3 c}$, respectively. To cancel out the effect of any abiotic factors in phenol removal, the loss of phenol from culture media without microalgae was determined, and a $1 \%$ abiotic loss of phenol was found within 4 days. This proves that the microalgae cells were solely responsible for phenol removal from the sample. The results show that the fastest phenol concentration drop recorded was using Pseudochlorococcum sp.

The effectiveness of phenol removal at each initial phenol concentration may not be clearly evident from the results shown in Figure 3 , as it shows the concentration of remaining phenol over initial phenol concentration that differs from one test to another.
Therefore, the rate of the drop of phenol concentration with time was determined, and shown in Figure 4, for the three tested strains. Since the interest is mainly on in the initial drop rate, the measurement of phenol concentration was limited to the first three days. As

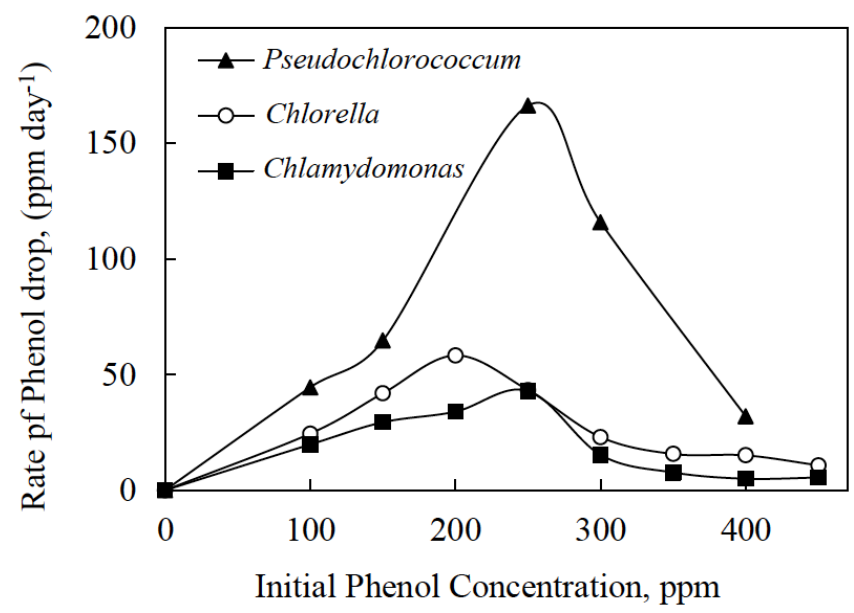

Figure 4: Phenol drop rate using Chlorella $s p$., Pseudochlorococcum sp. and Chlamydomonas sp. at various initial phenol concentrations. 
expected, up to an initial phenol concentration of 250 $\mathrm{ppm}$, the phenol drop rate increased with the increase in initial phenol concentration, which corresponds well with the growth results shown in Figure 2. However, for Chlorella sp., the maximum drop was observed at initial phenol concentration of $200 \mathrm{ppm}$. The results found in this work agree with those found using $C$. pyrenoidosa [17]. However, as mentioned earlier, in the latter work the substrate inhibition was encountered at $125 \mathrm{ppm}$.

\subsection{Kinetics of Cells Growth}

Three growth models were used to describe the specific growth rate of the tested strains. The selected models are those that incorporate limiting substrateinhibition kinetics, namely Haldane (Eq.1), Aiba (Eq.2) and Andrews (Eq.3)

$\mu=\frac{\mu_{m} S_{i}}{K_{S}+S_{i}+S_{i}^{2} / K_{i}}$

$\mu=\frac{\mu_{m} S_{i}}{K_{S}+S_{i}} \exp \left(-S / K_{i}\right)$

$\mu=\frac{\mu_{\mathrm{m}}}{\left[\left(\mathrm{K}_{\mathrm{S}} / \mathrm{S}_{\mathrm{i}}\right)+1\right] \cdot\left[1+\left(\mathrm{S} / \mathrm{K}_{\mathrm{i}}\right)\right]}$

Where, $\mu_{m}$ is the maximum specific growth rate, $S_{i}$ is the initial substrate concentration, $\mathrm{K}_{\mathrm{s}}$ is the substrate constant and $\mathrm{K}_{\mathrm{i}}$ is the inhibition constant. All the models were fitted to the experimental data shown in Figure 2. The estimated values for the model kinetic parameters as returned by the fitting non-linear regression algorithm, using Excel solver with an objective function (O.F.) given by Eq. (4), are shown in Table 1.

O.F $=\sum_{\mathrm{i}}^{\mathrm{n}}\left(\mu_{\exp }-\mu_{\text {pred. }}\right)^{2}$

Where, $\mu_{\exp }$ and $\mu_{\text {pred }}$ are the experimental and model predicted specific growth rates, respectively, and $n$ is the number of points used.

It is clear that the three models fittings are very close. The determined values of the model parameters were found to be close to those found using $C$. pyrenoidosa [17]. It was not possible to compare the results with other studies done on microalgae growth in phenolic media, because as mentioned earlier, they did not include kinetics studies. Graphical outputs showing the fits of the experimental data by the models are shown in Figure $\mathbf{5 a}, \mathbf{5 b}$ and $\mathbf{5 c}$, for Chlorella $s p$., Pseudochlorococcum sp. and Chlamydomonas sp., respectively.

\section{CONCLUSION}

The effect of initial phenol concentration on the growth of Chlorella sp., Pseudochlorococcum sp. and Chlamydomonas $s p$. has been tested. It was found that the specific growth rates of the tested strains increase with the increase in phenol concentration up to an optimum concentration of $250 \mathrm{ppm}$, and then start to

Table 1: Estimated Value of Microalgae Growth Kinetic Parameters in Phenol-Containing Media

\begin{tabular}{|c|c|c|c|}
\hline Strain & $\mu_{m}\left(\right.$ day $\left.^{-1}\right)$ & $\mathrm{K}_{\mathrm{s}}(\mathbf{p p m})$ & $\mathrm{K}_{\mathrm{i}}(\mathrm{ppm})$ \\
\hline \multicolumn{4}{|c|}{ Haldane Model } \\
\hline Chlorella & 0.43 & 145.58 & 177.51 \\
\hline Pseudochlorococcum sp & 0.88 & 45.17 & 142.64 \\
\hline Chlamydomonas $s p$ & 0.96 & 135.46 & 157.32 \\
\hline C. pyrenoidosa [17] & 0.55 & 89.99 & 100.24 \\
\hline \multicolumn{4}{|c|}{ Aiba Model } \\
\hline Chlorella & 0.45 & 85.24 & 291.97 \\
\hline Pseudochlorococcum sp & 1.32 & 109.46 & 86.23 \\
\hline Chlamydomonas $s p$ & 1.56 & 85.23 & 291.98 \\
\hline C. pyrenoidosa [17] & 0.71 & 58.13 & 200.40 \\
\hline \multicolumn{4}{|c|}{ Andrews Model } \\
\hline Chlorella & 0.63 & 150.79 .39 & 141.82 \\
\hline Pseudochlorococcum sp & 1.74 & 70.90 & 70.92 \\
\hline Chlamydomonas & 2.64 & 355.10 & 45.15 \\
\hline
\end{tabular}



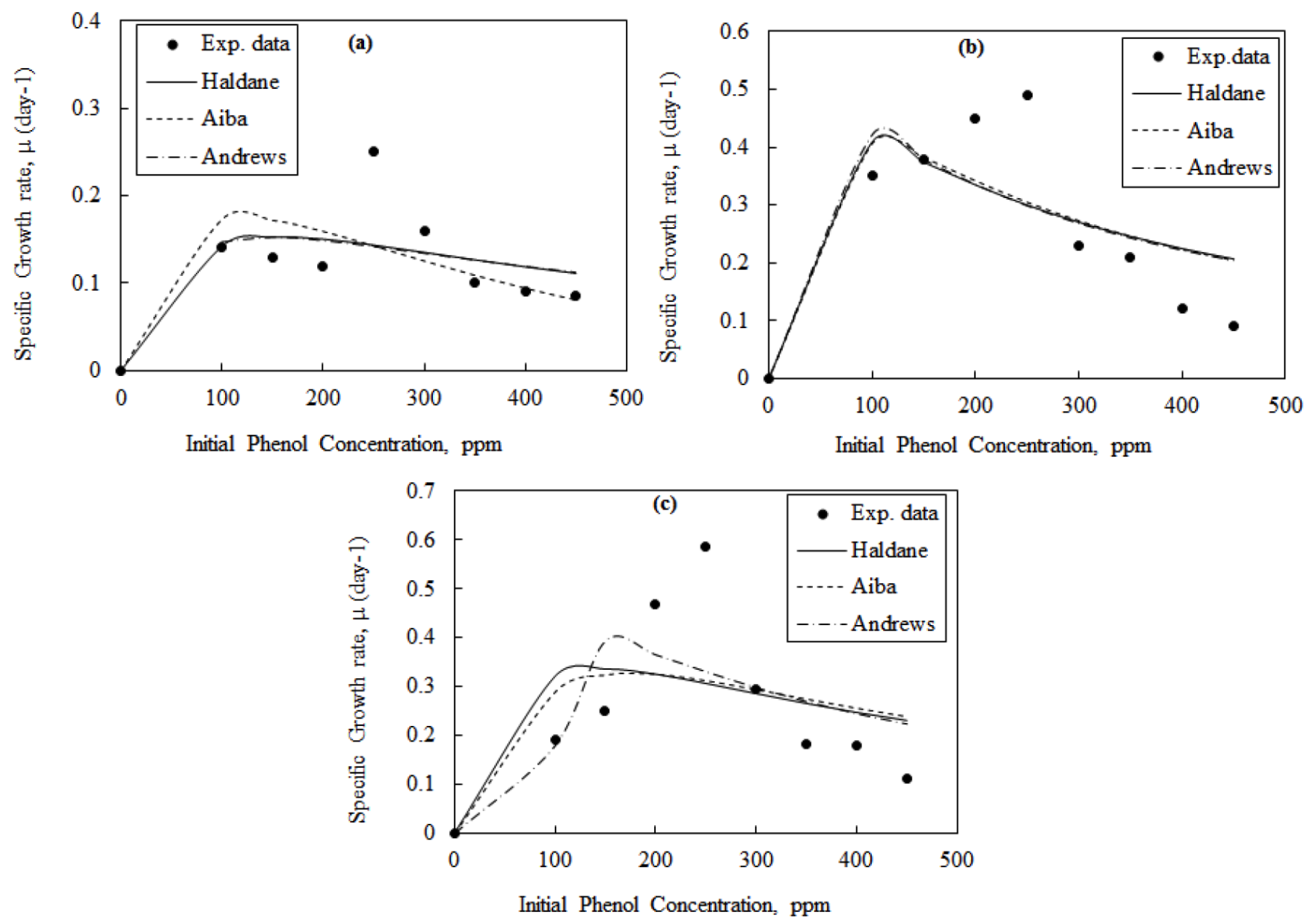

Figure 5: Growth kinetics model predictions of the specific growth rate of (a) Chlorella sp., (b) Pseudochlorococcum sp. and (c) Chlamydomonas $s p$. at various initial phenol concentrations.

drop. The effect of initial phenol concentration on the drop of phenol was also tested. The fastest phenol concentration drop recorded was using Pseudochlorococcum sp. Up to an initial phenol concentration of $250 \mathrm{ppm}$, the phenol drop rate increased with the increase in initial phenol concentration, and a drop in phenol degradation rate was observed beyond that concentration. It was found that reducing the illumination intensity enhanced the phenol drop rate and increased the inhibition onset concentration. Three kinetics models were used to describe growth rate, and their fittings were very close.

\section{ACKNOWLEDGEMENTS}

The authors would like to acknowledge the financial support provided by the Emirates Center for Energy and Environment Research (Fund No. 31R070). The authors' gratitude is also extended to Prof. Koroush Salihi from New York University in Abu Dhabi, UAE for providing samples of Chlamydomonas $s p$ used in this work.

\section{REFERENCES}

[1] Yan J, Jianping W, Jing B, Daoquan W, Zongding H. Phenol biodegradation by the yeast Candida tropicalis in the presence of m-cresol. Biochem Eng J 2006; 29: 227-34. http://dx.doi.org/10.1016/j.bej.2005.12.002

[2] Abdelwahab O, Amin NK, El-Ashtoukhy ESZ. Electrochemical removal of phenol from oil refinery wastewater. J Hazard Mater 2009; 163: 711-6. http://dx.doi.org/10.1016/j.jhazmat.2008.07.016

[3] Kumar A, Kumar S, Kumar S. Biodegradation kinetics of phenol and catechol using Pseudomonas putida MTCC 1194. Biochem Eng J 2009; 22: 151-9. http://dx.doi.org/10.1016/..bej.2004.09.006

[4] Nuhoglu A, Yalcin B. Modelling of phenol removal in a batch reactor. Process Biochem 2005; 40: 1233-9. http://dx.doi.org/10.1016/j.procbio.2004.04.003

[5] Ryan MP, Pembroke JT, Adley CC. Ralstonia pickettii in environmental biotechnology: potential and applications. $J$ Appl Microbiol 2007; 103: 754-64. http://dx.doi.org/10.1111/j.1365-2672.2007.03361.x

[6] El-Naas MH, Al-Zuhair S, Makhlouf S. Batch degradation of phenol in a spouted bed bioreactor system. Ind Eng Chem 2010; 16: 267-72. http://dx.doi.org/10.1016/j.jiec.2009.09.072

[7] El-Naas MH, Al-Zuhair S, Makhlouf S. Continuous biodegradation of phenol in a spouted bed bioreactor (SBBR). Chem Eng J 2010; 160: 565-70. http://dx.doi.org/10.1016/..cej.2010.03.068 
[8] Christenson L, Sims R. Production and harvesting of microalgae for wastewater treatment, biofuels, and bioproducts. Biotechnol Adv 2011; 29: 686-702. http://dx.doi.org/10.1016/j.biotechadv.2011.05.015

[9] Amaro HM, Barros R, Guedes AC, Sousa- Pinto I, Malcata FX. Microalgal compounds modulate carcinogenesis in the gastrointestinal tract. Trends Biotechnol 2013; 31: 92-8. http://dx.doi.org/10.1016/j.tibtech.2012.11.004

[10] Klekner V, Kosaric N. Degradation of phenols by algae. Environ Technol 1992; 13: 493-501. http://dx.doi.org/10.1080/09593339209385176

[11] Semple KT, Cain RB. Biodegradation of phenols by the alga Ochromonas danica. Applied and Environ Microbiol 1996; 62: 1265-73.

[12] Pinto G, Pollio A, Previtera L, et al. Removal of low molecular weight phenols from olive oil mill wastewater using microalgae. Biotechnol Lett 2003; 25: 1657-59. http://dx.doi.org/10.1023/A:1025667429222

[13] El-Sheekh M, Ghareib MM, Abou-EL-Souod GW. Biodegradation of phenolic and polycyclic aromatic compounds by some algae and cyanobacteria. J Bioremediat Biodegrad 2012; 3: 133-42.
[14] Scragg AH. The effect of phenol on the growth of Chlorella vulgaris and Chlorella VT-1. Enzyme Microb Technol 2006; 39: 796-9. http://dx.doi.org/10.1016/j.enzmictec.2005.12.018

[15] Mahiudddin M, Fakhruddin ANM, Al-Mahin A. Degradation of phenol via meta cleavage pathway by Pseudomonas fluorescens PU1. ISRN Microbiol 2012; Article ID 741820.

[16] Leonard D, Lindley ND. Carbon and energy flux constraints in continuous cultures of Alcaligenes eutrophus grown on phenol. Microbiol 1998; 144: 241-8. http://dx.doi.org/10.1099/00221287-144-1-241

[17] Das B, Mandal TK, Patra S. A comprehensive study on Chlorella pyrenoidosa for phenol degradation and its potential applicability as biodiesel feedstock and animal feed. Appl Biochem Biotechnol 2015; 176: 1382-401. http://dx.doi.org/10.1007/s12010-015-1652-9

[18] Taher $\mathrm{H}$, Al-Zuhair S, AlMarzoqui A, et al. Growth of microalgae using $\mathrm{CO}_{2}$ enriched air for biodiesel production in supercritical $\mathrm{CO}_{2}$. Renewable Energy 2015; 82: 61-7. http://dx.doi.org/10.1016/j.renene.2014.08.013

\section{DOI: http://dx.doi.org/10.6000/1927-3037.2016.05.02.2}

(c) 2016 Al-Zuhair et al.; Licensee Lifescience Global.

This is an open access article licensed under the terms of the Creative Commons Attribution Non-Commercial License (http://creativecommons.org/licenses/by-nc/3.0/) which permits unrestricted, non-commercial use, distribution and reproduction in any medium, provided the work is properly cited. 